\title{
Evaluation of the Prevalence of Facet Joint Pain in Chronic Thoracic Pain
}

\author{
Laxmaiah Manchikanti, MD*, Vijay Singh, MD**, Vidyasagar Pampati, MSc\#, Carla D. Beyer, RN"\# \\ and Kim S. Damron, RN"\#
}

The role of zygapophysial (facet) joints in chronic thoracic pain has received very little attention with only a few publications discussing these joints as sources of pain. In contrast, facet joints have been implicated as responsible for chronic pain in a significant proportion of patients with chronic neck and low back pain. However, thoracic spinal pain, though less common, has been reported to be as disabling as neck and low back pain.

This study was designed to evaluate all the consecutive patients presenting with thoracic pain and undergoing diagnostic medial branch blocks during 2001. All the patients failed conservative management with physical therapy, chiropractic therapy and drug therapy. All patients underwent diagnostic facet joint nerve blocks using lidocaine $1 \%$, initially followed by bupivacaine $0.5 \%$ on

Zygapophysial (facet) joints have been implicated as the source of chronic pain in $15 \%$ to $45 \%$ of patients with chronic low back pain (1-7) and $54 \%$ to $60 \%$ of patients with chronic neck pain (8-10). These figures were based on responses to controlled diagnostic blocks of these joints, in accordance with the criteria established by the International Association for the Study of Pain (11). However, the role of thoracic facet joints in chronic upper or mid back pain has received very little attention with only a few publications discussing these joints as the source of pain production (12-19). Even though thoracic spinal pain is less common, it can be as chronic and disabling as

From Pain Management Center of Paducah, Paducah, Kentucky and Pain Diagnostics Associates, Niagara, Wisconsin. *Dr. Manchikanti is the medical director at Pain Management Center of Paducah, **Dr. Singh is the medical director at the Pain Diagnostics Associates, ${ }^{\#} \mathrm{Mr}$.

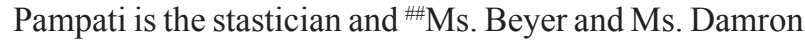
are clinical coordinators at Pain Management Center of Paducah. Address correspondence: Laxmaiah Manchikanti, MD, 2831 Lone Oak Road, Paducah, KY 42003. E-mail: drm@apex.net

Funding: No financial support was obtained for this study. separate occasions.

Results showed that 46 patients underwent single blocks with lidocaine and 36 of these patients, or $78 \%$, were positive for facet joint pain, reporting a definite response. Confirmatory blocks with bupivacaine were performed in all patients who were lidocaine-positive, with $61 \%$, or $48 \%$ of the total sample of the lidocaine-positive group, reporting a definite response with improvement in their pain. Thus, comparative local anesthetic blocks showed the prevalence of facet joint pain to be $48 \%$, with single blocks carrying a false-positive rate of $58 \%$.

Keywords: Chronic thoracic pain, zygapophysial joints, facet joints, medial branch blocks, controlled diagnostic blocks, false-positive rate

neck and low back pain. In the interventional pain management environment, the proportion of patients with thoracic disorders is relatively small ranging from $3 \%$ to $22 \%(20,21)$. Linton et al (22) estimated the prevalence of all spinal pain in the general population as $66 \%$, with $15 \%$ reporting thoracic pain, $44 \%$ reporting neck pain and $56 \%$ reporting low back pain. Edmondson and Singer (23) showed that even though the mechanical thoracic spine pain is less common, it can be as disabling as lumbar or cervical pain. Occhipiniti et al (24), in a survey of factory workers described a prevalence of thoracic pain of $5 \%$, in contrast to the prevalence of cervical and lumbar pain of $24 \%$ and $33 \%$ respectively. They also showed that in spite of the lower prevalence, the degree of disability resulting from thoracic pain disorders was similar to that of other regions. Occupations requiring sustained sitting have been described to predisposed to thoracic spine pain. Anderson et al (25) described a prevalence of thoracic pain in bus drivers of $28 \%$, in contrast to $10 \%$ in nondrivers. However, in both groups, the prevalence of cervical and lumbar pain was also considerably higher. Upon summarizing selected surveys, Singer and Edmondson (20) found that the reported incidence of the occurrence of musculoskeletal complaints attributed to the thoracic region was $2 \%$ to $26 \%$, and its prevalence was $5 \%$ to $34 \%$. 
In experimental studies, cervical, thoracic and lumbar facet joint pain has been evaluated by intraarticular joint injections under fluoroscopic guidance. These injections have been shown to cause capsular distention resulting in local and referred pain $(12,26-28)$. Referral patterns for the cervical, thoracic and lumbar facet joints have been presented based on the results of these injections. Bogduk (29) postulated that for any structure to be deemed a cause of back pain, it should have a nerve supply; should be capable of causing pain similar to that seen clinically, ideally in normal volunteers; should be susceptible to diseases or injuries that are known to be painful; and should have been shown to be a source of pain in patients, using diagnostic techniques of known reliability and validity. Bogduk (30) also postulated that diagnostic blockade of a structure with a nerve supply with the ability to generate pain, can be performed to test the hypothesis that the target structure is a source of the patient's pain.

In accordance with postulates of Bogduk $(29,30)$, the thoracic facet joints are (or appear to be) innervated and they produce pain in normal volunteers $(12,13,31-41)$. But, to date, there is no known pathology and relief of pain has not been demonstrated by using diagnostic techniques of known reliability and validity in thoracic spinal pain.

Due to the paucity of published evidence, the prevalence of thoracic facet joint pain is not known and the utility of thoracic facet joint blocks is, as yet, only conjectural (29). There is no evidence that thoracic facet joint pain can be diagnosed by clinical examination or by medical imaging (30). The principles established for cervical and lumbar facet joint blocks utilizing controlled comparative local anesthetic blocks also apply to thoracic facet joints and are probably the only means available to identify facet joint pain in the thoracic region. These joints can be blocked either by intraarticular injections or by anesthetizing the medial branches of the dorsal rami that innervate the target joint. This study was undertaken to determine the frequency of the involvement of the facet joints in the causation of chronic thoracic pain by controlled comparative local anesthetic diagnostic blocks.

\section{METHODS}

This study was designed to evaluate all the consecutive patients presenting with chronic thoracic pain, managed by one physician and undergoing diagnostic medial branch blocks, in a non-university setting, in one private comprehensive interventional pain management practice during 2001. Inclusion criteria included the failure of conservative management with physical therapy, chiropractic management and drug therapy; patients aged from 18 years to 90 years; those patients without a radicular pattern of pain; those patients without disc herniation on MRI; and those who had pain for at least 6 months. Evaluation of all the patients included a comprehensive evaluation with the completion of a comprehensive pain management questionnaire, history, physical examination and evaluation of the results of all procedures and investigations. All of the patients consented and participated in the study after the nature of the study and potential hazards of the procedures were explained to them. A total of 46 patients participated in the evaluation.

All patients underwent diagnostic facet joint nerve blocks using lidocaine $1 \%$, initially followed by bupivacaine $0.5 \%$ on separate occasions, usually 3 to 4 weeks apart. Injectate was prepared by mixing equal volumes of Sarapin to $2 \%$ lidocaine and $0.5 \%$ bupivacaine, with addition of $2 \mathrm{mg}$ of methylprednisolone to each $\mathrm{mL}$ of mixture. The blocks were performed on the ipsilateral side in patients with unilateral pain or bilaterally in patients with bilateral or axial pain. Blocks were performed at least at two levels to block a single joint. Blocks were performed with a 22gauge, 2-inch spinal needle under intermittent fluoroscopic visualization at each of the medial branches. Each nerve was infiltrated with a mixture of $0.5 \mathrm{~mL}$ of either $1 \%$ lidocaine or $0.25 \%$ bupivacaine. Levels varied from T3/ 4-T11/12, with involvement of mostly two to four joints on each side. Levels were selected based on any of the findings including the history of distribution of pain and tenderness in the paramedian region or area overlying the facet joint, and/or reproduction of symptoms with pressure. A definite response was defined as relief of pain of at least $80 \%$ in the symptomatic area. Following each block, the patient was examined and previously painful movements were performed. In order to be considered positive, the response to a block had to last at least 2 hours or longer when lidocaine was used; and at least 3 hours or longer, when bupivacaine was used.

Those patients who were shown to be negative to lidocaine block or confirmatory block with bupivacaine, underwent other diagnostic and/or therapeutic blocks, with further investigation and management. Target points were based on the descriptions of Bogduk (30). In general, the superolateral corners of the thoracic transverse processes were considered as target points. Bogduk (30) described the nerves to a particular joint to be the ones that crossed the transverse process above the joint and the transverse 
Table 1. Demographic features

\begin{tabular}{|c|c|c|}
\hline & & $\mathrm{N}=46$ \\
\hline \multirow{2}{*}{ Gender } & Male & $33 \%(15)$ \\
\hline & Female & $67 \%(31)$ \\
\hline \multirow{2}{*}{ Age (yrs.) } & Range & $25-83$ \\
\hline & Mean \pm SEM & $46 \pm 2.2$ \\
\hline \multirow{2}{*}{ Height (inches) } & Range & $59-76$ \\
\hline & Mean \pm SEM & $67 \pm 0.6$ \\
\hline \multirow{2}{*}{ Weight (lbs.) } & Range & $100-330$ \\
\hline & Mean \pm SEM & $169 \pm 5.9$ \\
\hline \multirow{2}{*}{ Duration of Pain (months) } & Range & $6-600$ \\
\hline & Mean \pm SEM & $86 \pm 17.2$ \\
\hline \multirow{2}{*}{ Onset of Pain } & Gradual & $61 \%(28)$ \\
\hline & Following an incident & $39 \%(18)$ \\
\hline
\end{tabular}

process below the joint. T1-T4, T9/10 blocks were performed by advancing the needle until contact was made with the back of the target transverse process. Subsequently, the needle was adjusted so as to rest on the back of the superolateral corner of the transverse process. For medial branch blocks from T5 to T8, the needle made contact with the rib lying at the same depth as the back of the transverse process. For medial branch blocks at T11 and T12, the target point was at the junction of the superior articular process and the transverse process, which the target nerve crosses. All blocks were performed under fluoroscopic visualization by one investigator, with the patient in prone position in an operating room. Intravenous access and mild sedation with midazolam were carried out in all the patients.

Data were recorded on a database using Microsoft ${ }^{\circledR}$ Access. The SPSS version 9.0 statistical package was used to generate frequency tables.

\section{RESULTS}

Table 1 illustrates demographic features of patients studied and salient characteristics of thoracic pain with duration and mode of onset.

Description of number of patients receiving medial branch blocks is illustrated in Table 2. The majority of the patients received medial branch blocks to block two joints. In addition, $57 \%$ of the patients underwent bilateral medial branch blocks.

Table 3 describes the evaluation of thoracic facet joint pain. All 46 patients underwent single blocks with lidocaine. Thirty-six patients, or $78 \%(95 \%$ CI, $66 \%$, $90 \%$ ), of the patients were positive for facet joint pain

Table 2. Description of number of patients receiving medial branch blocks

\begin{tabular}{lcccc}
\hline Levels block & Bilateral & Left & Right & Total \\
\hline Four joints & 5 & 2 & 1 & 9 \\
Three joints & 9 & 3 & 4 & 16 \\
Two joints & 12 & 4 & 6 & 21 \\
Total number of patients & 26 & 9 & 11 & 46 \\
\hline
\end{tabular}


Table 3. Results of facet joint nerve block's (single blocks with lidocaine and double blocks with lidocaine and bupivacaine)

\begin{tabular}{lcc}
\hline & \multicolumn{2}{c}{ Double Blocks } \\
\cline { 2 - 3 } Single Block & Positive & Negative \\
\hline Positive & 22 & 14 \\
Negative & & 10 \\
Prevalence & $48 \%(95 \%$ CI $34 \%$ to $62 \%)$ \\
False positive rate & $58 \%(95 \%$ CI $38 \%$ to $78 \%)$ \\
\hline
\end{tabular}

reporting a definite response with a single block. Confirmatory blocks with bupivacaine were performed in all patients who were lidocaine-positive, with $48 \%$ (95\% CI, $34 \%, 62 \%)$, of the total sample, or $61 \%(95 \% \mathrm{CI}, 45 \%$, $77 \%$ ), of the lidocaine-positive group, reporting a definite response with improvement in their pain.

Thus, the double blocks showed the prevalence of thoracic facet joint pain in chronic thoracic pain to be $48 \%$. Single blocks carry a false-positive rate of $58 \%$ (95\% CI, 38\%, $78 \%$ ).

\section{DISCUSSION}

There are relatively few reports that document patterns of thoracic pain pathology, compared with the published literature on the lumbar and cervical regions. In addition, the focus has been on other structures capable of causing thoracic pain, including the disc, nerve roots, muscles, ligaments, and the costotransverse and costovertebral joints (14). The cervical and lumbar facet joints have received considerable attention and now are accepted as potential pain generators (30).

The prevalence of thoracic facet joint pain of $48 \%$ determined in this study is in the mid range between the facet joint pain in chronic low back pain with $15 \%$ to $45 \%$ (1-7) and cervical facet joint pain in chronic neck pain with $54 \%$ to $60 \%(8-10)$. The criteria adapted for the diagnosis of thoracic facet joint pain with comparative local anesthetic blocks in this study are similar to the criteria adapted in the evaluation of cervical and lumbar facet joint pain. Criticism may be forwarded that we have not utilized placebo-controlled diagnostic blocks. Instead, we have utilized controlled, comparative local anesthetic blocks of the medial branches, based on private practice settings and validation of controlled comparative local anesthetic blocks. Criticism may also be advanced based on the fact that we performed medial branch blocks, rather than intraarticular injections. However, the intraarticular blocks in the thoracic region at times are challenging to the clinician and painful for the patient. Further, one of the reported drawbacks of local anesthetic control is that comparative local anesthetic blocks may not be implementable for intraarticular blocks because it is not known whether the placement of local anesthetic in a relatively avascular environment, such as a joint space, affects its expected duration of action. Thus, we employed medial branch blocks utilizing comparative local anesthetic agents in all cases. There was also a significant false-positive rate of $58 \%$ with single blocks. Thus, once again, this validates the necessity of controlled, comparative local anesthetic blocks rather than a single block. The value of confirmatory blocks is demonstrated for thoracic facet joint blocks similar to lumbar and cervical zygapophysial (facet) joint blocks (5-7, 10, 30, 42, 43).

Chua and Bogduk (36) have described the anatomy of the medial branches. They showed that the medial branches of the thoracic dorsal rami do not assume the same course at different levels. The nerves at mid-thoracic levels do not run on bone. However, instead, they are suspended in the intertransverse space. Chua and Bogduk (36) also reported that the thoracic medial branches are not that close to the facet joint, as they swing laterally to circumvent the multifidus. Consequently, the target points for blocks of these nerves are relatively intangible and require judgments about how far to withdraw a needle from bone rather than resting the needle onto a radiographically visible bony landmark. However, earlier information with much of the systematic innervation of the human spine has been extrapolated from the comprehensive description of that in the monkey by Stilwell from 1956 (31). Free nerve endings have been demonstrated in the capsules of facet joints. In an analogy to the innervation of the cervical and lumbar facet joints, the thoracic facet joints receive a bisegmental innervation from the medial branches of the dorsal ramus of the upper segment and one or more cephalad level(s) $(32,36)$. Thus, facet joints T6/T7, for example, are supplied by $\mathrm{T} 5$ and T6 spinal nerves.

\section{CONCLUSION}

The results of this study show that facet joints are the responsible pain generators in $48 \%$ of the patients suffering with chronic thoracic pain after failure to respond to traditional conservative management with physical 
therapy, chiropractic management, and drug therapy. This study also reinforced the fact that single blocks are unreliable, similar to the results from cervical and lumbar facet joint medial branch blocks, with a false-positive rate of $58 \%$.

\section{ACKNOWLEDGMENTS}

The authors wish to thank Tonie Hatton, Marla Neihoff and Lorie Caldwell for their assistance in preparation of this manuscript.

\section{REFERENCES}

1. Schwarzer AC, Aprill CN, Derby R et al. Clinical features of patients with pain stemming from the lumbar zygapophysial joints. Is the lumbar facet syndrome a clinical entity? Spine 1994; 19:1132-1137.

2. Schwarzer AC, Wang S, Bogduk N et al. Prevalence and clinical features of lumbar zygapophysial joint pain: A study in an Australian population with chronic low back pain. Am Rheum Dis 1995; 54:100-106.

3. Schwarzer AC, Aprill CN, Derby R et al. The relative contributions of the disc and zygapophyseal joint in chronic low back pain. Spine 1994; 19:801-806.

4. Manchikanti L, Pampati VS, Fellows B et al. Prevalence of lumbar facet joint pain in chronic low back pain. Pain Physician 1999; 2:59-64.

5. Manchikanti L, Pampati VS, Bakhit CE et al. The diagnostic validity and therapeutic value of lumbar facet joint nerve blocks with or without adjuvant agents. Cur Rev Pain 2000; 4:337-344.

6. Manchikanti L, Pampati V, Fellows B et al. The inability of the clinical picture to characterize pain from facet joints. Pain Physician 2000; 3:158-166.

7. Manchikanti L, Singh V, Pampati VS et al. Evaluation of the relative contributions of various structures in chronic low back pain. Pain Physician 2001; 4:308316.

8. Barnsley L, Lord SM, Wallis BJ et al. The prevalence of chronic cervical zygapophyseal joint pain after whiplash. Spine 1995; 20:20-26.

9. Lord SM, Barnsley L, Wallis BJ et al. Chronic cervical zygapophysial joint pain with whiplash: A placebocontrolled prevalence study. Spine 1996; 21:17371745.

10. Manchikanti L, Singh V, Rivera J et al. Prevalence of cervical facet joint pain in chronic neck pain. Pain Physician 202; 5:243-249.

11. Merskey H, Bogduk N. Classification of chronic pain: Descriptions of chronic pain syndromes and definitions of pain terms. Second Edition. IASP Press, Seattle, 1994

12. Dreyfuss P, Tibiletti C, Dreyer SJ. Thoracic zygapophyseal joint pain patterns: A study in normal volunteers. Spine 1994; 19:807-811.

13. Dreyfuss P, Tibiletti C, Dreyer S et al. Thoracic zygapophyseal pain: A review and description of an intraarticular block technique. Pain Digest 1994; 4:44-52.

14. Skubic JW, Kostuik JP. Thoracic pain syndromes and thoracic disc herniation. In Frymoyer JW (ed). The Adult Spine. Raven Press, New York, 1991:14431461.

15. Wilson PR. Thoracic facet joint syndrome - A clinical entity? Pain Suppl 1987; 4:S87.

16. Stolker RJ, Vervest AC, Groen GJ. Percutaneous facet denervation in chronic thoracic spinal pain. Acta Neurochir 1993; 122:82-90.

17. Stolker RJ, Vervest AC, Groen GJ. Parameters in electrode positioning in thoracic percutaneous facet denervation: An anatomical study. Acta Neurochir 1994; 128:32-39.

18. Stolker RJ, Vervest AC, Groen GJ. The treatment of chronic thoracic segmental pain by radiofrequency percutaneous partial rhizotomy. J Neurosurg 1994; 80:986-992.

19. Stolker RJ, Vervest AC, Ramos LM et al. Electrode positioning in thoracic percutaneous partial rhizotomy: An anatomical study. Pain 1994; 57:241251

20. Singer KP, Edmondston SJ. Introduction: The enigma of the thoracic spine. In Giles GF, Singer KP (eds). Clinical Anatomy and Management of Thoracic Spine Pain. Butternorth Heineman, Boston, 2000; pp 315.

21. Manchikanti L, Pampati V. Research designs in interventional pain management: Is randomization superior, desirable or essential? Pain Physician 2002; 5:275-284

22. Linton SJ, Hellsing AL, Hallden K. A population based study of spinal pain among 35-45-year old individuals. Spine 1998; 23:1457-1463.

23. Edmondson SJ, Singer KP. The thoracic spine: Anatomical and biomechanical considerations for manual therapy. Man Ther 1997; 2:132-143.

24. Occhipiniti E, Colombini D, Grieco A. Study of distribution and characteristics of spinal disorders using a validated questionnaire in a group of male subjects not exposed to occupational spinal risk factors. Spine 1993; 18:1150-1159.

25. Anderson R, Meeker WC, Wieick BE et al. A metaanalysis of clinical trials of spinal manipulation. JMPT 1992; 15:181-194.

26. Dwyer A, Aprill C, Bogduk N. Cervical zygapophyseal joint pain patterns I: A study in normal volunteers. Spine 1990; 15:453-457.

27. McCall IW, Park WM, O'Brien JP. Induced pain referral from posterior lumbar elements in normal subjects. Spine 1979; 4:441-446.

28. Mooney V, Roberston J. The facet syndrome. Clin Orthop 1976; 115:149-156. 
29. Bogduk N (ed). Low back pain. Clinical anatomy of lumbar spine and sacrum. Third edition. Churchill Livingstone, New York, 1997; pp 187-213.

30. Bogduk N. International Spinal Injection Society guidelines for the performance of spinal injection procedures. Part 1: Zygapophyseal joint blocks. Clin J Pain 1997; 13:285-302.

31. Stilwell DL. The nerve supply of the vertebral column and its associated structures in the monkey. Anat Rec 1956; 125:139-169.

32. Stolker RJ, Vervest AC, Groen GJ et al. On the innervation of the dorsal compartment of the thoracic spine. In Stolker RJ, Vervest AC (eds). Pain Management by Radiofrequency Procedures in the Cervical and Thoracic Spine: A Clinical and Anatomical Study. Thesis, Utrecht; 1994; pp 133-144.

33. Lazorthes G. Les branches postérieures des nerves rachidians et le plan articulaire vertebral postérieur. Ann Med Phys 1972; 15:192-202.

34. Maigne JY, Maigne R. Guérin-Surville H. Upper thoracic dorsal rami: Anatomic study of their medial cutaneous branches. Surg Radiol Anat 1991; 13:109112.

35. Groen GJ, Baljet B, Drukker J. Nerves and nerve plexuses of the human vertebral column. Am J Anat $1990 ; 188: 282-296$.
36.

Chua WH, Bogduk N. The surgical anatomy of thoracic facet denervation. Acta Neurochir 1995; 136:140-144.

37. Giles LG, Taylor JR. Innervation of lumbar zygapophyseal joint synovial folds. Acta Orthop Scand 1987; 58:43-46.

38. Giles LG, Taylor JR. Intraarticular synovial protrusions in the lower lumbar apophyseal joints. Bull Hosp Joint Dis 1982; 42:248-255.

39. Giles LG, Taylor JR, Cockson A. Human zygapophyseal joint synovial folds. Acta Anat 1986; 126:110-114.

40. Giles LG, Harvey Ar. Immunohistochemical demonstration of nociceptors in the capsule and synovial folds of human zygapophyseal joints. $\mathrm{Br} \mathrm{J}$ Rheumatol 1987; 26:362-364.

41. Groen SJ, Stolker RJ. Thoracic neural anatomy. In Giles GF, Singer KP (eds). Clinical Anatomy and Management of Thoracic Spine Pain. Butternorth Heineman, Boston, 2000; pp 3-15.

42. Schwarzer AC, Aprill CN, Derby R et al. The falsepositive rate of uncontrolled diagnostic blocks of the lumbar zygapophysial joints. Pain 1994; 58:195-200.

43. Barnsley L, Lord S, Wallis B et al. False-positive rates of cervical zygapophysial joint blocks. Clin $J$ Pain 1993; 9:124-130. 